\title{
Stability of avocado oil during heating: comparative study to
}

\section{olive oil"}

Izaskun Berasategi $^{1}$, Blanca Barriuso ${ }^{1}$, Diana Ansorena ${ }^{1 *}$, Iciar Astiasarán ${ }^{1}$

${ }^{1}$ Department of Nutrition, Food Science, Physiology and Toxicology, Faculty of Pharmacy, University of Navarra, Irunlarrea s/n, 31008-Pamplona, Spain.

*Corresponding author: Tel.: +34 948425600 (ext. 6263); Fax: +34 948425649.

E-mail address: $\underline{\text { dansorena@unav.es }}$ 


\section{INTRODUCTION}

Cold-pressed avocado oil is relatively new in culinary circles, and its production volume is relatively small compared with other oils, with approximately 2000 tonnes /year. New Zealand, Mexico, Chile, United States and South Africa are among the main avocado oil producers. Its significant production, commercialization and marketing are only occurring in the twenty-first century and limited published information still exists on this product (Woolf et al., 2008).

Avocado oil has the advantage, as it occurs with olive oil, which can be obtained from the fruit by means of a cold extraction method, which is an easy, low cost technology that allows maintaining in the oil significant amounts of the bioactive phytochemicals present in the fruit. It should be also mentioned that, when obtained by non cold-press extraction procedures, the extraction methods applied for obtaining avocado oil can modify the physical and chemical characteristics of the final product (Ortiz-Moreno, Dorantes, Galindez \& Guzman, 2003).

As it has been also pointed out for other types of oils, avocado oil could be used as an ingredient in functional foods because of its high concentration of oleic monounsaturated fatty acid, and substantial amounts of health beneficial compounds, such as antioxidant vitamins and phytosterols (Requejo, Ortega, Robles, Navia, Faci \& Aparicio, 2003). In vitro and in vivo studies indicate that avocado fruit can be considered as part of a cancer prevention diet because of their high content of phytochemicals (Ding, Chin, Kinghorn, D’Ambrosio \& Steven, 2007), being particularly significant in this sense the lipid-soluble bioactive substances (Lu, Arteaga, Zhang, Huerta, Go \& Heber, 2005).

Compared to other fruits, avocado contains a high amount of sterols which are extracted together with some other unsaponifiable components with the oil. Woolf et al. (2008) 
pointed out that the concentration of sterols in avocado oil is around $3.3 \mathrm{mg} / \mathrm{g}$ oil with up to 4.5 in some cases (being the main compound $\beta$-sitosterol) being significantly higher than that in olive oil.

Plant sterols, or phytosterols, are triterpene compounds, similar in structure to cholesterol, that are found in plants. They can be divided into three main classes: 4desmethylsterols, 4-methylsterols, and 4,4'-dimethylsterols (triterpene alcohols). Many studies that demonstrated that 4-desmethylsterols have healthy benefits, such as the decrease in the LDL cholesterol. Also, they possess anticancer, anti-inflammatory, antiatherogenic, and antioxidative activities (Berger, Jones \& Abumweis, 2004). Some studies have shown that phytosterols may have a protective effect in oils heated to frying temperatures (White \& Armstrong, 1986). Regarding 4,4'-dimethylsterols, although some healthy properties have been described for some of them, they have been mainly used to oil identification purposes (Azadmard-Damirchi, Savage \& Dutta, 2005). They have shown antimicrobial, cytotoxic, antitumoral, antiviral, antiinflammatory, hepatoprotective, antifeedant and insecticidal activities (Alvarenga \& Esteban, 2005).

Vegetable oils are usually used raw in salads, but also they are used to cook, using for different culinary processes. In these cases, oils are heated to high temperatures. These temperatures could produce degradation and oxidation of compounds of oils, resulting in damaging substances for health (Soupas, Juntunen, Saynajoki, Lampi \& Piironen, 2004). These reactions depend on the conditions of the culinary process (temperature and time), the type of oil used and the type of fried product (Lampi, Juntunen, Toivo \& Piironen, 2002; Rudzinska, Korczak \& Wasowicz, 2005; Kmiecik, Korczak, Rudzinska, 
Gramza-Michalowska \& Hes, 2009). Moreover, vegetable oils are rich in unsaturated fatty acids, which are less stable to oxidation than saturated fatty acids (Choe \& Min, 2007). Olive oil has been established more stable than other vegetal oils to thermal degradation due to its high amount of MUFA (Koski et al., 2002) and to the content of phenolic compounds (Teissedre \& Waterhouse, 2000).

As avocado oil has not been considered as an important source of oil, few studies have been developed about its properties for culinary application.

The objective of this work was to study the stability of the saponifiable and unsaponifiable fractions of avocado oil under a drastic heating treatment and to compare it to that of olive oil.

\section{MATERIALS AND METHODS}

\subsection{Materials}

The oils used in this study were Extra Virgin Olive Oil (Koipe, Sos Corporación Alimentaria, S.A., Madrid, Spain) and Avocado Oil (Denova Products cc, Louis Trichardt, South Africa), which is derived from the first pressing of the mature fruit

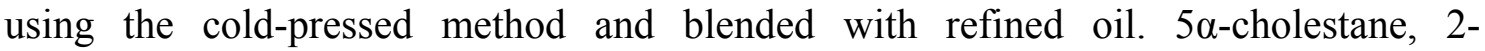
thiobarbituric acid, $\alpha$-tocopherol acetate $98 \%, \alpha$-tocopherol $97 \%$, tetraethoxypropane and fatty acid methyl esters were purchased from Sigma-Aldrich Chemical (Steinheim, Germany). Tri-sil reagent was obtained from Thermo Scientific (Bellefont, PA, USA). Boron trifluoride/methanol and BHT were obtained from Merck (Whitehouse Station, NJ, USA). KOH, hexane, cyclohexanone, methanol, hydrochoric acid, trichloroacetic acid and ammonium sulphate were from Panreac (Barcelona, Spain). Ethanol was purchased from Oppac (Navarra, Spain) and HPLC grade methanol from Scharlab (Barcelona, Spain). 


\subsection{Heating study}

For the heating study, sets of $5 \mathrm{~g}$ of both oils were placed into test tubes $\left(\right.$ PYREX $^{\circledR}$ Culture Tubes 16x100 SVL SCRE) and subjected to an intensive heat treatment. The test tubes were placed in the thermo block (Temblock, Selecta ${ }^{\circledR}$, Spain) previously stabilized at $180{ }^{\circ} \mathrm{C}$. Test tubes were left open and removed from the thermo block at different heating times up to 9 hours. Then, the samples were cooled in an ice bath for 20 minutes. Finally, the tubes were covered and stored in the freezer $\left(-20^{\circ} \mathrm{C}\right)$ until analysis.

\subsection{Oil analysis}

\subsubsection{Fatty acid profile}

Fatty acids were determined in the oils by gas chromatography FID detection, previous preparation of the fatty acid methyl esters derivatives. Boron trifluoride/methanol was used for the preparation of fatty acid methyl esters (AOAC, 2002). A Perkin-Elmer Clarus 500 gas chromatograph, equipped with a split-splitless injector, automatic autosampler, and coupled to a computerized system for data adquisition (TotalChrom, version 6.2.1) was used. It was fitted with a capillary column $\mathrm{SP}^{\mathrm{TM}}-2560(100 \mathrm{~m} \times 0.25$ $\mathrm{mm} \times 0.2 \mu \mathrm{m})$. The temperature of both the injection port was $250{ }^{\circ} \mathrm{C}$ and detector was $260{ }^{\circ} \mathrm{C}$, the oven temperature was programmed to increase from 170 to $200{ }^{\circ} \mathrm{C}$ at a rate of $10.0{ }^{\circ} \mathrm{C} / \mathrm{min}$ and then at rate of $4.0^{\circ} \mathrm{C} / \mathrm{min}$ to $220^{\circ} \mathrm{C}$. The carrier gas was hydrogen, 30.0 psi. The sample size was $0.5 \mu 1$ and the split ratio was 120 . The quantification of individual fatty acids used heptadecanoic acid methyl ester as internal standard. The identification of the fatty acids was done by comparison of their retention times with 
those of pure fatty acid methyl esters. The sampling times for this parameter were 0,3 and 9 hours.

\subsubsection{Determination of Sterols}

Three grams $( \pm 0.02 \mathrm{~g})$ of oil sample and $1 \mathrm{~mL}$ of internal standard ( $5 \alpha$-Cholestane: 2 $\mathrm{mg} / \mathrm{mL}$ chloroform) were subjected to saponification and further extraction of the unsaponifiable fraction. Ethanol $(20 \mathrm{~mL})$ and $\mathrm{KOH}(50 \%)(5 \mathrm{~mL})$ were added to the sample and subjected to a warm agitation for $1 \mathrm{~h}\left(<50^{\circ} \mathrm{C}\right) .13 \mathrm{~mL}$ of distillated water were added and six extractions with $20-25 \mathrm{~mL}$ of hexane were done, collecting the organic phase of each extraction, which were all merged. Solvent was rotavaporated and the sample was further dried under nitrogen flow. This unsaponifiable fraction was derivatized with $400 \mu \mathrm{L}$ of Tri-Sil in a hot water bath $\left(60^{\circ} \mathrm{C}\right.$ for 45 minutes $)$ to form the trimethyl silyl ether (TMS) derivatives. The excess of Tri-Sil was evaporated under nitrogen flow and the sample was diluted in $10 \mathrm{~mL}$ of hexane. The TMS derivatives of sterols were analyzed in an HP 6890 GC system (Hewlett-Packard, Palo Alto, USA) coupled to a 5973 Mass Selective Detector (Hewlett-Packard). $1 \mu \mathrm{L}$ was injected into GC, equipped with a capillary column (30 m x $250 \mu \mathrm{m}$ x $0.25 \mu \mathrm{m}$ nominal HP-5MS). The carrier gas was $\mathrm{He}(1 \mathrm{~mL} / \mathrm{min})$, and the chromatographic conditions were as follows: initial oven temperature was maintained during $0.5 \mathrm{~min}$ at $85{ }^{\circ} \mathrm{C}$ and subsequently programmed from 85 to $290{ }^{\circ} \mathrm{C}$ at a rate of $50{ }^{\circ} \mathrm{C} / \mathrm{min}$ and at a rate of 0.5 ${ }^{\circ} \mathrm{C} / \mathrm{min}$ from 290 to $298{ }^{\circ} \mathrm{C}$. The injector and the detector temperatures were set at 280 ${ }^{\circ} \mathrm{C}$ and $300{ }^{\circ} \mathrm{C}$, respectively. Acquisition mass range was established between 50.00 and 550.00 uma. Electron impact at $70 \mathrm{eV}$. Identification of the peaks was based on comparison of their mass spectra with the spectra of the Wiley library (HPCHEM, Wiley, 275, $6^{\text {th }}$ ed.) and also with those obtained from the literature. In some cases, a 
comparison of their retention time and MS fragments with those of TMS ether derivatives prepared from standard pure compounds was also done.

The amounts of the different sterols during the analytical procedure in oils were calculated on basis on the amount of a specific ion for each peak (Table 2), and taking into account the relative proportion in which this ion is present in each compound:

$$
\text { mg sterol } / 100 \text { g oil }=100 *\left(\mathrm{PA}_{\mathrm{s}}^{*} \mathrm{~F}\right)\left(\mathrm{m}_{\mathrm{is}}\right) /\left(\mathrm{PA}_{\mathrm{is}}\right)(\mathrm{m})
$$

$P A_{s}=$ sterol peak area on ion basis

$F=$ proportion in which the ion is present in the peak

$P A_{i s}=$ internal standard peak area

$m_{i s}=$ weight $(m g)$ of the internal standard

$m=$ weight $(g)$ of oil taken for analysis

The sampling times for this parameter were 0,3 and 9 hours.

\subsubsection{TBARs value}

TBARS values were determined on oil basis according to the method described by Maqsood \& Benjakul (2010) with slight modifications. Briefly, the TBARS reagent was prepared by mixing $15 \% \mathrm{w} / \mathrm{v}$ trichloroacetic acid, $0.0375 \% \mathrm{w} / \mathrm{v} 2$-thiobarbituric acid in $0.25 \mathrm{~N}$ hydrochloric acid. The oil $(0.5 \mathrm{~g})$, distillate water $(0.5 \mathrm{~mL}), 20 \mu \mathrm{L}$ of BHT $(1 \%)$ and the TBARS reagent $(2 \mathrm{~mL})$ were vortexed in a centrifuge tube immediately after combining, for $30 \mathrm{sec}$, placed in a boiling water bath for exactly $15 \mathrm{~min}$ and then cooled in an ice bath to room temperature. Cyclohexanone $(4 \mathrm{~mL})$ and ammonium sulphate $(1$ $\mathrm{mL}, 4 \mathrm{M})$ were added to the mixture and were vortexed for $30 \mathrm{sec}$. The mixture was centrifuged at room temperature at $4000 \mathrm{rpm}$ for 10 minutes. The supernatant was collected and the absorbance was measured at $532 \mathrm{~nm}$. A calibration curve with TEP (tetraethoxypropane) was done for quantification purposes, using the same procedure as 
with the sample. Results were expressed in mg of malondialdehyde (MDA) equivalents/ $\mathrm{kg}$ product. The sampling times for this parameter were $0,0.5,2,3,6$ and 9 hours.

\subsubsection{Tocopherol analysis}

The determination of the tocopherol content in the oils was done by HPLC-UV analysis. $0.1 \mathrm{~g}$ of oil and $0.1 \mathrm{~mL}$ of internal standard ( $\alpha$-tocopherol acetate $10 \mathrm{mg} / \mathrm{mL}$ solved in methanol) were filled up to $10 \mathrm{~mL}$ with previously warmed $\left(30^{\circ} \mathrm{C}\right)$ supergradient HPLC grade methanol. Dilution was vortexed for $30 \mathrm{sec}$ and filtered with $0.20 \mu \mathrm{m}$ filter (Syringe-driven Filter Unit, Millex ${ }^{\circledR}$ ).

UV spectra were recorded on a Perkin Elmer UV-Vis Lambda 200 Series equipped with a photodiode array detector Series 200 PDA, using a Supercosil LC18 column (25 mm x $4.6 \mathrm{~mm}, 5 \mu \mathrm{m}$ particle size; Perkin Elmer Brownlee columns, Massachusetts, USA). A total of $1 \mu \mathrm{L}$ of the sample was injected into HPLC and isocratic elution with Methanol/Water (97:3) at $1.5 \mathrm{ml} / \mathrm{min}$ flow. The UV acquisition was recorded at $292 \mathrm{~nm}$ for 12 min run. Identification of $\alpha$-Tocopherol was done using the retention time of the pure standard compound $(\mathrm{RT}=4.5 \mathrm{~min})($ Vitamin E $97 \%)$ and its characteristic UV spectra. The quantification was performed using a calibration curve previously plotted with Tocopherol acetate $(\mathrm{RT}=7.5 \mathrm{~min})($ Vitamin E acetate $98 \%$ ). The sampling times for this parameter were $0,1,2,3,4$ and 5 hours.

\subsection{Statistical analysis}

Data were analyzed using $t$ student test for the evaluation of the results obtained in two oils in the same time of heating process. A one way Anova test and the Tukey $b$ post hoc test were used to determine significant differences among the different times of heating process for the same oil. Correlation between TBARs and vitamin E content 
was evaluated by Pearson's correlation test. SPSS version 15.0 was used (SPSS inc. Chicago, Illinois, USA). Significance level of $p \leq 0.05$ was used for all evaluations.

\section{RESULTS AND DISCUSSION}

\subsection{Avocado oil vs. olive oil}

As in the case of olive oil, the beneficial health properties of avocado oil could be attributed to its composition, a high MUFA content and a significant amount of minor components with interesting physiological activities (antioxidant and hipocholesterolemic effects). The fatty acid profiles of two the oils were presented in table 1 .

MUFA amount of avocado oil sample was high (68.4\%), reaching oleic acid $54.4 \%$ of total FA. These data are in agreement with those of Ortiz Moreno et al. (2003) who found oleic acid amounts in the range of 52-60\% depending on the oil extracting methods used. Wang, Hwang, Yoon \& Choe (2001) reported higher mean values for Hass avocado oil from different countries (61.7-77.8\%). Other MUFA present in significant amount were palmitoleic $(7.9 \%)$ and vaccenic $(5.9 \%)$ acids. Plaza, Sanchez-Moreno, de Pascual-Teresa, de Ancos \& Cano (2009) found $57 \%$ of oleic acid of the total fatty acids and lower $(6 \%)$ and higher $(9 \%)$ amounts for palmitoleic and vaccenic acids (both MUFA), respectively. Compared to olive oil, the MUFA content was significantly lower, especially due to the higher amount of oleic acid shown by olive oil, which, at the same time, showed lower amounts for palmitoleic and vaccenic acids. The lower MUFA content showed by avocado oil was partially compensated by its higher PUFA content, containing interesting amounts of both omega- 6 and omega-3 fatty acids. Avocado oil contained more than 2-fold the amount of linoleic acid present in olive oil, being this acid quantitatively the third fatty acid in both types of oils. Also 
$\alpha$-linolenic was slightly, but significantly higher in avocado oil compared to olive oil. Trans fatty acids amount was $0.52 \%$ in avocado oil, slightly higher than the amount detected in olive oil $(0.33 \%)$. Ortiz Moreno et al. (2003) found values for total trans fatty acids in avocado oil between 0.33 to $0.87 \%$ depending on the method of extraction used. In that work the use of microwave and squeezing resulted in the lowest trans fatty acids content, whereas the use of acetone increased the trans content up to $0.87 \%$.

These differences detected in the fatty acids profile gave rise to some significant differences in the ratios with interest from the nutritional point of view. The ratio PUFA/SFA was higher in avocado oil than in olive oil, whereas PUFA+MUFA/SFA was lower. Moreover, $\omega-6 / \omega-3$ ratio was higher in avocado oil (14.05) than in olive oil (8.41), due to the high amount of linoleic acid $(\omega-6)$. Regarding these two last data, avocado oil did not show from the nutritional standpoint, an advantage compared to olive oil.

The unsaponifiable fraction of avocado oil showed also some significant differences compared to olive oil. The differences between the two oils were illustrated in figure 1 and table 2, where two TIC GC-MS chromatograms are shown, one for each type of oil. As it can be observed, some coleutions were noticed, and the different ions used for the monitorization and quantification of the compounds by SIM mode (single ion monitoring) analysis are shown. The most abundant compound in both oils was sitosterol, as it will be discussed below, that corresponded to peak G. The peak that followed sitosterol contained mainly $\Delta 5$-avenasterol, accompanied by sitostanol at the leading edge and by $\alpha$-amyrine at the tailing edge. Similarly, a coleution is observed for peaks compressed within RR between 1.07 and 1.08 , which were identified as $\Delta 7$ sitostanol, cycloartenol, cycloeucalenol and $\Delta 7$ - avenasterol, according to literature MS 
data. Five of the quantified compounds in this work were not identified or found in the literature. These compounds accounted for a 4.4 and $11.5 \%$ in olive oil and avocado oil, respectively. Further studies are needed to understand better these compounds, both in their characterization, as well as in their potential effects on health.

As it was expected, the amount of sterols in the avocado oil was much higher than that of olive oil, 339.64 and $228.27 \mathrm{mg} / 100 \mathrm{~g}$ oil, respectively (Table 3). Phytosterols content in vegetables are known to vary by different factors as variety, season, extraction and other technological procedures (Li, Beveridge \& Drover, 2007; Cercaci, Passalacqua, Poerio, Rodriguez-Estrada \& Lercker, 2007). American ginseng seed oil, which is considered as a potential functional ingredient by its high phytosterol content shows amounts around 798-973 mg/100 g oil (Beveridge, Li \& Drover, 2002).

The most abundant sterols in avocado oil were the 4-desmethyl-sterols, reaching the 80 $\%$ of the total fraction. Sitosterol was the most abundant sterol in this fraction and also considering the total sterols content, showing more than twice the amount detected in olive oil (251 vs. 93 mg/100 g oil). Tabee, Azadmard-Damirchi, Jagerstad \& Dutta (2008) found levels of sitosterol from 46.1 to $406 \mathrm{mg} / 100 \mathrm{~g}$ in different types of oils, including palm oil (with the lowest content) and rapeseed oil (with the highest content). Also other 4-desmethylsterols are present in avocado oil in significant amounts as campesterol (18 mg/100 g), $\Delta 5$-avenasterol (9.4 mg/100 g), $\Delta$ 7-sitosterol (2.8 mg/100 $\mathrm{g})$, sitostanol $(2.2 \mathrm{mg} / 100 \mathrm{~g})$ and stigmasterol $(1.1 \mathrm{mg} / 100 \mathrm{~g})$. The other two fractions, 4-monomethyl and 4,4'-dimethylsterols, were $2.7 \%$ and $5.5 \%$ from the total sterols with citrostadienol and cycloartenol, as the main compounds from each one.

The analysis of the olive oil sterol profile was significantly different. It showed percentages of $48.4 \%, 3.2 \%$ and $44.0 \%$ for 4-desmethyl, 4-monomethyl and 4,4'- 
dimethylsterols, respectively, being these results similar to those found by D'Evoli et al. (2006) and by Azadmard-Damirchi, Nemati, Hesari, Ansarin \& Fathi-Achachlouei (2010) in virgin olive oil. Sakouhi, Absalon, Flamini, Cioni, Kallel \& Boukhchina (2010) found a similar profile for 4-desmethylsterols in Sayoli olive oil. However, these authors found differences among vegetable oils for 4,4-dimethylsterols. In fact, the detection of trace levels of certain 4,4-dimethylsterols has been proposed as possible markers to detect virgin olive oil adulteration with hazelnut oil (Azadmard-Damirchi et al., 2010b).

The analysis of vitamin $\mathrm{E}$ showed much higher amounts of vit $\mathrm{E}$ in olive oil than in avocado oil (35.5 and $24.5 \mathrm{mg}$ vit E/100 g oil, respectively). Results obtained for olive oil agree with those obtained by Pellegrini, Visioli, Buratti \& Brighenti (2001). Lozano, Dhuique, Bannon \& Gaydou (1993) analyzed the vit E content in avocado oil depending on the degree of fruit maturation, finding that oil from mature fruits had lower amount of vit E than oil from immature fruits $(5.7-10.3 \mathrm{mg} / 100 \mathrm{~g}$ oil - 20.1-45.6 mg/100 $\mathrm{g}$, respectively). Salgado, Danieli, Bismara Regitano-D'Arce, Frias, \& Mansi (2008) analyzed avocado oil and they found $6.04 \mathrm{mg} / 100 \mathrm{~g}$ oil, much lower amount than that obtained in this work.

\subsection{Effects of heating treatment}

Oil behaviour during heating was evaluated by the evolution of TBARs (Figure 1) and also through the analysis of the modifications suffered both by the saponifiable (fatty acids, Table 1) and the unsaponifiable fractions, including the analysis of vitamin $\mathrm{E}$ along the heating treatment (Figure 2).

TBARs measure the formation of products derived from fatty acids oxidation. Comparing the fatty acid profile at 0 and $3 \mathrm{~h}$ of heating it can be observed that SFA 
increased in $0.46 \mathrm{~g}$ and $0.18 \mathrm{~g}$ in avocado and olive oils, whereas the unsaturated fraction (MUFA+PUFA) decreased in $0.52 \mathrm{~g}$ and $0.23 \mathrm{~g}$ in avocado and olive oils, respectively. These results corresponded to the increment for TBARs found during the first hours of heating (1, 2, 3 and 6 hours). TBARs was slightly higher in avocado than in olive oil before heating, and during the first 2 hours of treatment, it showed a similar increment in both oils $(+0.35$ and +0.49$)$. After that, the magnitude in the increment was higher in olive oil than in avocado oil $(+2.03$ and +1.04 , respectively) reaching the maximum values at $6 \mathrm{~h}$. It has to be remembered that unsaturated fatty acids are more prone to oxidation than SFA. There were no data available for fatty acids at 6 hours of heating but analyzing the evolution from 3 to 9 hours it can be observed that SFA increased in $0.31 \mathrm{~g}$ in olive oil and decreased in $0.46 \mathrm{~g}$ in avocado oil. On the contrary, the unsaturated fraction decreased in $0.33 \mathrm{~g}$ in olive oil and increase in $0.62 \mathrm{~g}$ in avocado oil. Allouche, Jimenez, Gaforio, Uceda \& Beltran (2007) found that, after $6 \mathrm{~h}$ treatment $\left(180^{\circ} \mathrm{C}\right)$ of olive oil, palmitoleic, linoleic and linoleic acid decreased, whereas oleic acid was not modified. Plaza et al. (2009) found a significant decrease in avocado fatty acids content during 13 days of cold storage. In the case of TBARs, although a similar decrease was observed for both oils during the last 3 hours, data showed significantly higher TBARs in olive than in avocado oil. These data pointed out to a higher stability of the saponificable fraction of avocado oil during heating.

The oils stability against oxidation depends not only on the degree of unsaturation, but also on the amount of antioxidants present in the unsaponifiable fraction. Tabee et al. (2008) analyzing the stability of oils with similar MUFA content during heating, showed different results depending on the amounts of $\alpha$-tocopherol and phytosterols present in the oils. 
The contribution of total tocopherols to extra virgin olive oil stability has been established to be around $9 \%$ (Aparicio, Roda, Albi \& Gutierrez, 1999). D’Evoli et al. (2006) found a different sterol degradation rate on extra virgin olive oil with and without the addition of rosemary, with known antioxidant properties. These authors observed a significant reduction of the sterol content after $6 \mathrm{~h}$ heating at $180^{\circ} \mathrm{C}$, remaining only a $67 \%$ of the initial amount present in olive oil. The experimental conditions used in that work ( $1 \mathrm{~g}$ sample heated) differed from our work (5 g sample heated), and could have definitively influenced the obtained results. As it can be seen in table 3, during the heating treatment, avocado oil maintained a higher amount of phytosterols than olive oil. However, the percentage of loss was different depending on the oil.

Only the compounds that appeared in low amounts disappeared with heating process, but most of the sterols, although significantly reduced, did not totally disappear. Regarding olive oil, after $3 \mathrm{~h}$ heating, a $93 \%$ of the initial sitosterol content remained, whereas after 9 h, a $90 \%$ remained. Regarding avocado oil, a $76 \%$ and $86 \%$ of the initial sitosterol content remained after heating 3 and $9 \mathrm{~h}$, respectively. According to what occurred with fatty acids of avocado oil at $9 \mathrm{~h}$ of heating, total phytosterols increased significantly. Winkler, Warner \& Glynn (2007) in an interesting paper over the effect of deep-fat frying on phytosterol content in different oils (olive and avocado oils not included) concluded that their loss appear to be unrelated either to fatty acid composition or to the extent of oil degradation.

Vitamin $\mathrm{E}$ is sensitive to heat treatment. It disappeared after 4 and $5 \mathrm{~h}$ of treatment in avocado and olive oil, respectively. The decrease was quicker in avocado oil, reaching at $2-3 \mathrm{~h}$ a $57 \%$ of loss, in contrast with the $26 \%$ of loss in the case of olive oil. The decrease of vitamin E amounts showed a high correlation with the increase of TBARs 
during the first $6 \mathrm{~h}$ ( $\mathrm{R}$ Pearson was -0.908 and -0.912 for olive and avocado oils, respectively; $\mathrm{p}<0.001)$.

In conclusion, avocado oil showed higher PUFA/SFA ratio and higher omega-6/omega3 ratio than olive oil. The amount of the main sterol, sitosterol, was more than 2 -fold abundant in avocado oil compared to olive oil. Whereas 4-desmethylsterols were predominant in avocado oil, 4-desmethylsterols and 4,4-dimethylsterols were similarly distributed in olive oil. According to TBARs results and the lipid profile, the stability of avocado oil during heating at $180^{\circ} \mathrm{C}$ was similar to that of olive oil.

\section{ACKNOWLEDGEMENTS}

We thank the "Programa Consolider-Ingenio 2010 CARNISENUSA CSD2007-00016", the "Proyecto AGL2008-01099/ALI" (Ministerio de Ciencia e Innovación), and "Plan Investigador de la Universidad de Navarra" (PIUNA) for their contribution to the financial support of this work. I. Berasategi is grateful to Gobierno de Navarra (Departamento de Innovación, Empresa y Empleo) and to "Asociación de Amigos de la Universidad de Navarra" for the grants received. We are also grateful to Denova Products for the supply of Avocado oil. 


\section{BIBLIOGRAPHY}

Allouche, Y., Jimenez, A., Gaforio, J. J., Uceda, M., \& Beltran, G. (2007). How heating affects extra virgin olive oil quality indexes and chemical composition. Journal of Agricultural and Food Chemistry, 55, 9646-9654.

Alvarenga, N., \& Ferro, E. A. (2005). Bioactive triterpenes and related compounds from celastraceae. Bioactive Natural Products (Part K), 30, 635-702.

AOAC. (2000). Methyl esters of fatty acids in oils and fats. 969.33. Official methods of analysis. $17^{\text {th }}$ Edition (Chapter 41, pp. 19-20). Gaithersburg, Maryland: Association of Official Analytical Chemists.

Aparicio, R., Roda, L., Albi, M. A., \& Gutierrez, F. (1999). Effect of various compounds on virgin olive oil stability measured by rancimat. Journal of Agricultural and Food Chemistry, 47(10), 4150-4155.

Azadmard-Damirchi S, Savage GP, \& Dutta PC (2005). Sterol fractions in hazelnut and virgin olive oils and 4,4'-dimethylsterols as possible markers for detection of adulteration of virgin olive oil. Journal of the American Oil Chemists' Society, 82(10), 82 (10) $717-725$.

Azadmard-Damirchi, S., Nemati, M., Hesari, J., Ansarin, M., \& Fathi-Achachlouei, B. (2010). Rapid separating and enrichment of 4,4'-dimethylsterols of vegetable oils by solid-phase extraction. Journal of the American Oil Chemists' Society, 87(10), 11551159.

Berger, A., Jones, P., \& Abumweis, S. (2004). Plant sterols: factors affecting their efficacy and safety as functional food ingredients. Lipids in Health and Disease, 3(1), 5. 
Beveridge, T. H. J., Li, T. S. C., \& Drover, J. C. G. (2002). Phytosterol content in American ginseng seed oil. Journal of Agricultural and Food Chemistry, 50(4), 744750.

Cercaci, L., Passalacqua, G., Poerio, A., Rodriguez-Estrada, M. T., \& Lercker, G. (2007). Composition of total sterols (4-desmethyl-sterols) in extravirgin olive oils obtained with different extraction technologies and their influence on the oil oxidative stability. Food Chemistry, 102(1), 66-76.

Choe, E., \& Min, D. B. (2007). Chemistry of deep-fat frying oils. Journal of Food Science, 72(5), R77-R86.

D'Evoli, L., Huikko, L., Lampi, A. M., Lucarini, M., Lombardi-Boccia, G., Nicoli, S., \& Piironen, V. (2006). Influence of rosemary (Rosmarinus officinalis, L.) on plant sterol oxidation in extra virgin olive oil. Molecular Nutrition \& Food Research, 50(9), 818823.

Ding, H., Chin, Y., Kinghorn, A. D., \& D’Ambrosio, S. M. (2007). Chemopreventive characteristics of avocado fruit. Seminars in cancer biology, 17(5), 386-394.

Kmiecik, D., Korczak, J., Rudzinska, M., Gramza-Michalowska, A., \& Hes, M. (2009). Stabilization of phytosterols in rapeseed oil by natural antioxidants during heating. European Journal of Lipid Science and Technology, 111(11), 1124-1132.

Koski, A., Psomiadou, E., Tsimidou, M., Hopia, A., Kefalas, P., Wahala, K., \& Heinonen, M. (2002). Oxidative stability and minor constituents of virgin olive oil and cold-pressed rapeseed oil. European Food Research and Technology, 214(4), 294-298. 
Lampi, A. M., Juntunen, L., Toivo, J., \& Piironen, V. (2002). Determination of thermooxidation products of plant sterols. Journal of Chromatography B-Analytical Technologies in the Biomedical and Life Sciences, 777(1-2), 83-92.

Li, T. S. C., Beveridge, T. H. J., \& Drover, J. C. G. (2007). Phytosterol content of sea buckthorn (Hippophae rhamnoides L.) seed oil: Extraction and identification. Food Chemistry, 101(4), 1633-1639.

Lozano, Y.F., Dhuique Mayer, C., Bannon, C., \& Gaydou, E.M. (1993). Unsaponifiable matter, total sterol and tocopherol contents of avocado oil varieties. Journal of the American Oil Chemists' Society, 70(6), 561-565.

Lu, Q., Arteaga, J. R., Zhang, Q., Huerta, S., Go, V. L. W., \& Heber, D. (2005). Inhibition of prostate cancer cell growth by an avocado extract: role of lipid-soluble bioactive substances. The Journal of nutritional biochemistry, 16(1), 23-30.

Maqsood, S., \& Benjakul, S. (2010). Comparative studies of four different phenolic compounds on in vitro antioxidative activity and the preventive effect on lipid oxidation of fish oil emulsion and fish mince. Food Chemistry, 119(1), 123-132.

Ortiz-Moreno, A., Dorantes, L., Galindez, J., \& Guzman, R. (2003). Effect of different extraction methods on fatty acids, volatile compounds, and physical and chemical properties of avocado (Persea americana Mill.) oil. Journal of Agricultural and Food Chemistry, 51(8), 2216-2221.

Pellegrini, N., Visioli, F., Buratti, S., \& Brighenti, F. (2001). Direct analysis of total antioxidant activity of olive oil and studies on the influence of heating. Journal of Agricultural and Food Chemistry, 49(5), 2532-2538. 
Plaza, L., Sanchez-Moreno, C., de Pascual-Teresa, S., de Ancos, B., \& Cano, M. P. (2009). Fatty acids, sterols, and antioxidant activity in minimally processed avocados during refrigerated storage. Journal of Agricultural and Food Chemistry, 57(8), 32043209.

Requejo, A. M., Ortega, R. M., Robles, F., Navia, B., Faci, M., \& Aparicio, A. (2003). Influence of nutrition on cognitive function in a group of elderly, independently living people. European journal of clinical nutrition, 57, S54-S57.

Rudzinska, M., Korczak, J., \& Wasowicz, E. (2005). Changes in phytosterols and their oxidation products during frying of French fries in rapeseed oil. Polish Journal of Food and Nutrition Sciences, 14(4), 381-387.

Sakouhi, F., Absalon, C., Flamini, G., Cioni, P. L., Kallel, H., \& Boukhchina, S. (2010). Lipid components of olive oil from Tunisian Cv. Sayali: Characterization and authenticity. Comptes Rendus Biologies, 333(9), 642-648.

Salgado, J. M., Danieli, F., Bismara Regitano-D'Arce, M. A., Frias, A., \& Mansi, D. N. (2008). The avocado oil (Persea americana Mill) as a raw material for the food industry. Ciencia E Tecnologia De Alimentos, 28, 20-26.

Soupas, L., Juntunen, L., Saynajoki, S., Lampi, A., \& Piironen, V. (2004). GC-MS method for characterization and quantification of sitostanol oxidation products. Journal of the American Oil Chemists' Society, 81(2), 135-141.

Tabee, E., Azadmard-Damirchi, S., Jagerstad, M., \& Dutta, P. C. (2008). Effects of alpha-tocopherol on oxidative stability and phytosterol oxidation during heating in some 
regular and high-oleic vegetable oils. Journal of the American Oil Chemists Society, 85(9), 857-867.

Teissedre, P. L., \& Waterhouse, A. L. (2000). Inhibition of oxidation of human lowdensity lipoproteins by phenolic substances in different essential oils varieties. Journal of Agricultural and Food Chemistry, 48(9), 3801-3805.

Wang, S., Hwang, H., Yoon, S., \& Choe, E. (2010). Temperature dependence of autoxidation of Perilla oil and tocopherol degradation. Journal of Food Science, 75(6), C498-C505.

White, P. J., \& Armstrong, L. S. (1986). Effect of selected oat sterols on the deterioration of heated soybean oil. Journal of the American Oil Chemists Society, 63(4), 525-529.

Winkler, J. K., Warner, K., \& Glynn, M. T. (2007). Effect of deep-fat frying on phytosterol content in oils with differing fatty acid composition. Journal of the American Oil Chemists Society, 84, 1023-1030.

Woolf, A., Wong, M., Eyres, L., McGhie, T., Lund, C., Olsson, S., Wang, Y., Bulley, C., Wang, M., Friel, E., \& Requejo-Jackman, C. (2008). Avocado oil. In R.A. Moreau, \& A. Kamal-Eldin (Eds.), Gourmet and health-promoting specialty oils (pp. 73-125). Urbana: AOCS Monograph Series on Oilseeds. 
Table 1. Fatty acid composition of the two types of oils in three times of heating process $(\mathrm{g} / 100 \mathrm{~g}$ fatty acids mean \pm standard deviation).

\begin{tabular}{|c|c|c|c|c|c|c|c|c|c|}
\hline & \multicolumn{2}{|c|}{ CONTROL } & \multirow[b]{2}{*}{$\mathbf{L S}^{2}$} & \multicolumn{2}{|c|}{3 HOURS } & \multicolumn{4}{|c|}{9 HOURS } \\
\hline & OLIVE $^{1}$ & AVOCADO $^{1}$ & & OLIVE $^{1}$ & AVOCADO $^{1}$ & $\mathbf{L S}^{\mathbf{2}}$ & OLIVE $^{1}$ & AVOCADO $^{1}$ & $\mathbf{L S}^{2}$ \\
\hline Myristic C14:0 & $0.02 \pm 0.00$ & $0.06 \pm 0.00^{a}$ & $* * *$ & $0.03 \pm 0.00$ & $0.06 \pm 0.00^{a b}$ & $* * *$ & $0.03 \pm 0.00$ & $0.06 \pm 0.00^{b}$ & $* * *$ \\
\hline Palmitic C16:0 & $10.24 \pm 0.02^{a}$ & $18.74 \pm 0.06^{a}$ & $* * *$ & $10.34 \pm 0.01^{b}$ & $19.18 \pm 0.02^{c}$ & $* * *$ & $10.56 \pm 0.00^{c}$ & $18.91 \pm 0.04^{b}$ & $* * *$ \\
\hline t-Palmitoleic C16:1t & $0.11 \pm 0.00^{a}$ & $0.10 \pm 0.00$ & $* * *$ & $0.12 \pm 0.00^{b}$ & $0.10 \pm 0.00$ & $* * *$ & $0.11 \pm 0.00^{a b}$ & $0.10 \pm 0.00$ & $* * *$ \\
\hline Palmitoleic C16:1 & $0.60 \pm 0.01^{a}$ & $7.88 \pm 0.01^{a b}$ & $* * *$ & $0.62 \pm 0.00^{c}$ & $7.85 \pm 0.05^{a}$ & $* * *$ & $0.62 \pm 0.00^{b}$ & $7.94 \pm 0.05^{b}$ & $* * *$ \\
\hline Stearic C18:0 & $3.12 \pm 0.01^{a}$ & $0.51 \pm 0.00^{a}$ & $* * *$ & $3.21 \pm 0.01^{b}$ & $0.53 \pm 0.01^{b}$ & $* * *$ & $3.29 \pm 0.01^{c}$ & $0.55 \pm 0.01^{c}$ & $* * *$ \\
\hline Elaidic C18:1t & $0.14 \pm 0.01$ & $0.29 \pm 0.02$ & $* * *$ & $0.15 \pm 0.02$ & $0.34 \pm 0.02$ & $* * *$ & $0.17 \pm 0.02$ & $0.33 \pm 0.01$ & $* * *$ \\
\hline 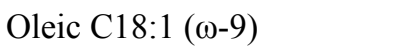 & $77.64 \pm 0.03^{c}$ & $54.40 \pm 0.10^{a}$ & $* * *$ & $77.35 \pm 0.02^{a}$ & $54.69 \pm 0.11^{b}$ & $* * *$ & $77.48 \pm 0.02^{b}$ & $54.46 \pm 0.09^{a}$ & $* * *$ \\
\hline Vaccenic C18:1 ( $\omega-7)$ & $2.16 \pm 0.02^{b}$ & $5.87 \pm 0.03^{b}$ & $* * *$ & $2.00 \pm 0.01^{a}$ & $5.88 \pm 0.06^{b}$ & $* * *$ & $2.15 \pm 0.02^{b}$ & $5.61 \pm 0.01^{a}$ & $* * *$ \\
\hline$t$-Linoleic C18:2t & $0.03 \pm 0.00^{c}$ & $0.02 \pm 0.00^{b}$ & $* *$ & $0.01 \pm 0.00^{a}$ & $0.02 \pm 0.00^{a}$ & $* * *$ & $0.01 \pm 0.00^{b}$ & $0.03 \pm 0.00^{c}$ & $* * *$ \\
\hline$c-t$ linoleic C18:1c.1t & $0.00 \pm 0.00^{a}$ & $0.03 \pm 0.00^{a}$ & $* * *$ & $0.04 \pm 0.00^{b}$ & $0.05 \pm 0.00^{c}$ & $* * *$ & $0.06 \pm 0.00^{c}$ & $0.04 \pm 0.00^{b}$ & $* * *$ \\
\hline$t-c$ linoleic C18:1t.1c & $0.05 \pm 0.00^{a}$ & $0.06 \pm 0.00^{a}$ & $* *$ & $0.05 \pm 0.00^{a b}$ & $0.07 \pm 0.00^{b}$ & $* *$ & $0.06 \pm 0.00^{b}$ & $0.06 \pm 0.00^{a}$ & $* *$ \\
\hline Linoleic C18:2 ( $\omega-6)$ & $4.21 \pm 0.01^{b}$ & $10.87 \pm 0.01^{b}$ & $* * *$ & $4.20 \pm 0.00^{b}$ & $10.24 \pm 0.03^{a}$ & $* * *$ & $3.79 \pm 0.01^{a}$ & $10.94 \pm 0.04^{c}$ & $* * *$ \\
\hline Arachidic C20:0 & $0.31 \pm 0.05$ & nd & & $0.31 \pm 0.00$ & nd & & $0.32 \pm 0.00$ & nd & \\
\hline 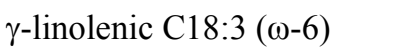 & $0.01 \pm 0.00$ & $0.01 \pm 0.00^{a}$ & ns & $0.01 \pm 0.00$ & $0.02 \pm 0.00^{c}$ & $\mathrm{~ns}$ & $0.01 \pm 0.00$ & $0.01 \pm 0.00^{b}$ & $* *$ \\
\hline Eicosenoic C20:1 ( $\omega-9)$ & $0.13 \pm 0.00^{a}$ & $0.12 \pm 0.00$ & ns & $0.15 \pm 0.00^{b}$ & $0.09 \pm 0.01$ & $* * *$ & $0.15 \pm 0.00^{b}$ & $0.11 \pm 0.00$ & $* * *$ \\
\hline$\alpha$-linolenic C18:3 ( $\omega-3)$ & $0.53 \pm 0.00^{b}$ & $0.61 \pm 0.00^{b}$ & $* * *$ & $0.53 \pm 0.01^{b}$ & $0.51 \pm 0.01^{a}$ & $* *$ & $0.42 \pm 0.01^{a}$ & $0.63 \pm 0.00^{c}$ & $* * *$ \\
\hline Eicosatrienoic C20:3 ( $\omega-3)$ & nd & $0.01 \pm 0.00^{b}$ & & nd & $0.01 \pm 0.00^{c}$ & & nd & nd & \\
\hline Arachidonic C20:4 $(\omega-6)$ & $0.63 \pm 0.02^{b}$ & $0.01 \pm 0.00^{a}$ & $* * *$ & $0.61 \pm 0.01^{b}$ & $0.01 \pm 0.00^{a}$ & $* * *$ & $0.50 \pm 0.01^{a}$ & $0.03 \pm 0.00^{b}$ & $* * *$ \\
\hline SFA & $13.71 \pm 0.02^{a}$ & $19.31 \pm 0.06^{a}$ & $* * *$ & $13.89 \pm 0.01^{b}$ & $19.77 \pm 0.03^{c}$ & $* * *$ & $14.20 \pm 0.01^{c}$ & $19.52 \pm 0.04^{b}$ & $* * *$ \\
\hline MUFA & $80.53 \pm 0.03^{c}$ & $68.40 \pm 0.09^{b}$ & $* * *$ & $80.13 \pm 0.02^{a}$ & $68.55 \pm 0.02^{c}$ & $* * *$ & $80.42 \pm 0.02^{b}$ & $68.15 \pm 0.05^{a}$ & $* * *$ \\
\hline PUFA & $5.43 \pm 0.03^{b}$ & $11.75 \pm 0.02^{b}$ & $* * *$ & $5.60 \pm 0.01^{c}$ & $11.08 \pm 0.06^{a}$ & $* * *$ & $4.98 \pm 0.03^{a}$ & $11.74 \pm 0.06^{b}$ & $* * *$ \\
\hline$\omega-3$ & $0.58 \pm 0.01^{a}$ & $0.78 \pm 0.01^{c}$ & $* * *$ & $0.70 \pm 0.00^{c}$ & $0.71 \pm 0.01^{b}$ & ns & $0.60 \pm 0.01^{b}$ & $0.67 \pm 0.02^{a}$ & $* *$ \\
\hline$\omega-6$ & $4.85 \pm 0.03^{b}$ & $10.97 \pm 0.01^{b}$ & $* * *$ & $4.91 \pm 0.01^{c}$ & $10.36 \pm 0.07^{a}$ & $* * *$ & $4.38 \pm 0.02^{a}$ & $11.06 \pm 0.04^{c}$ & $* * *$ \\
\hline$\omega-6 / \omega 3$ & $8.41 \pm 0.08^{c}$ & $14.05 \pm 0.15^{a}$ & $* * *$ & $7.02 \pm 0.04^{a}$ & $14.60 \pm 0.22^{b}$ & $* * *$ & $7.30 \pm 0.12^{b}$ & $16.44 \pm 0.41^{c}$ & $* * *$ \\
\hline PUFA/SFA & $0.40 \pm 0.00^{b}$ & $0.61 \pm 0.00^{c}$ & $* * *$ & $0.40 \pm 0.00^{c}$ & $0.56 \pm 0.00^{a}$ & $* * *$ & $0.35 \pm 0.00^{a}$ & $0.60 \pm 0.00^{b}$ & $* * *$ \\
\hline PUFA+MUFA/SFA & $6.27 \pm 0.01^{c}$ & $4.15 \pm 0.02^{c}$ & $* * *$ & $6.17 \pm 0.01^{b}$ & $4.03 \pm 0.01^{a}$ & $* * *$ & $6.02 \pm 0.00^{a}$ & $4.09 \pm 0.01^{b}$ & $* * *$ \\
\hline trans & $0.33 \pm 0.01^{a}$ & $0.52 \pm 0.02^{a}$ & $* * *$ & $0.38 \pm 0.02^{b}$ & $0.58 \pm 0.03^{b}$ & $* * *$ & $0.40 \pm 0.02^{b}$ & $0.56 \pm 0.01^{a b}$ & $* * *$ \\
\hline
\end{tabular}

${ }^{I}$ Within each type of oil, different letters in the same raw denote significant differences among times of analysis ( $\left.p<0.05\right)$. ${ }^{2} L S$ (level of significance of the t-student test that compares the two oils for each time of analysis): $n s$ (not significant); $p \geq 0.05 ; * * p<0.01 ; * * * p<0.001$.

nd: not detected

SFA: saturated fatty acids; MUFA: monounsaturated fatty acids; PUFA: polyunsaturated fatty acids 
Table 2. Retention times, relative retention times and fragmentation ions used in the identification of the trimethyl silyl ether derivatives of the sterols of olive and avocado oils.

\begin{tabular}{|c|c|c|c|c|c|c|c|}
\hline COMPOUND & $\begin{array}{c}\text { PEAK } \\
\text { (Figure 2) }\end{array}$ & OIL & RT & $\mathbf{R R}$ & TYPE & MAIN FRAGMENTATION IONS & REFERENCES \\
\hline Campesterol & $\mathrm{A}$ & $\mathrm{O} \& \mathrm{~A}$ & 11.46 & 0.91 & 4-DESM & $472 ; 457 ; 382 ; 367 ; \mathbf{3 4 3} ; 129$ & Standard \\
\hline Campestanol & $\mathrm{B}$ & $\mathrm{O} \& \mathrm{~A}$ & 11.50 & 0.91 & 4-DESM & $459 ; 382 ; 354 ; 241$ & Standard \\
\hline Stigmasterol & $\mathrm{C}$ & $\mathrm{O} \& \mathrm{~A}$ & 11.83 & 0.93 & 4-DESM & $\mathbf{4 8 4} ; 469 ; 394 ; 379 ; 355 ; 255 ; 145$ & Standard \\
\hline Unknown 1 & $\mathrm{D}$ & $\mathrm{O} \& \mathrm{~A}$ & 11.95 & 0.94 & - & $495 ; 131$ & \\
\hline Unknown 2 & $\mathrm{E}$ & $\mathrm{O} \& \mathrm{~A}$ & 12.27 & 0.97 & - & 414; $303 ; 223$ & \\
\hline Lanosterol & $\mathrm{F}$ & $\mathrm{O} \& \mathrm{~A}$ & 12.57 & 0.99 & 4-DIMS & $498 ; \mathbf{4 8 3} ; 393 ; 189$ & 2 \\
\hline Sitosterol & G & $O \& A$ & 12.66 & 1.00 & 4-DESM & $486 ; 471 ; 396 ; 381 ; 357$ & Standard \\
\hline Sitostanol & $\mathrm{H}$ & $\mathrm{O} \& \mathrm{~A}$ & 12.79 & 1.01 & 4-DESM & $488 ; 473 ; 215$ & Standard \\
\hline$\Delta 5$-Avenasterol & I & $\mathrm{O} \& \mathrm{~A}$ & 12.83 & 1.01 & 4-DESM & 386; 296 & $1 ; 3$ \\
\hline$\alpha$-amyrin & $\mathrm{J}$ & $\mathrm{O} \& \mathrm{~A}$ & 12.91 & 1.02 & 4-DIMS & $241 ; 218$ & $1 ; 3$ \\
\hline Lupeol + gramisterol & $\mathrm{K}$ & $\mathrm{O} \& \mathrm{~A}$ & 13.44 & 1.06 & 4-DIMS & $443 ; 400 ; \mathbf{3 5 7} ; 269$ & 2 \\
\hline$\Delta 7-$ Sitosterol & $\mathrm{L}$ & $\mathrm{O} \& \mathrm{~A}$ & 13.51 & 1.07 & 4-DESM & $471 ; 281 ; 255$ & $1 ; 3$ \\
\hline Cycloartenol & M & $\mathrm{O} \& \mathrm{~A}$ & 13.54 & 1.07 & 4-DIMS & $498 ; 483 ; \mathbf{4 0 8} ; 365$ & $2 ; 3$ \\
\hline Cycloeucalenol & $\mathrm{N}$ & $O \& A$ & 13.61 & 1.08 & 4-MS & $\mathbf{3 5 3} ; 283$ & 1 \\
\hline$\Delta 7$-Avenasterol & $\mathrm{O}$ & $\mathrm{O} \& \mathrm{~A}$ & 13.72 & 1.08 & 4-DESM & $469 ; 343$ & 2 \\
\hline Unknown 3 & $\mathrm{P}$ & A & 13.98 & 1.10 & - & $\mathbf{5 0 0} ; 462$ & \\
\hline Unknown 4 & Q & A & 14.30 & 1.13 & - & $440 ; \mathbf{4 1 2} ; 370$ & \\
\hline 24-Methylenecycloartanol & $\mathrm{R}$ & $\mathrm{O} \& \mathrm{~A}$ & 14.57 & 1.15 & 4-DIMS & $497 ; 422 ; 407 ; 379 ; 353$ & $1 ; 3$ \\
\hline Unknown 5 & $\mathrm{~S}$ & A & 14.71 & 1.16 & - & $444 ; 357 ; 317$ & \\
\hline Citrostadienol & $\mathrm{T}$ & $\mathrm{O} \& \mathrm{~A}$ & 15.28 & 1.21 & 4-MS & $400 ; 357 ; 267$ & $1 ; 3$ \\
\hline
\end{tabular}


Table 3. Phytosterol composition of the two types of oils in three times of heating process $(\mathrm{mg} / 100 \mathrm{~g}$ oil mean \pm standard deviation).

\begin{tabular}{|c|c|c|c|c|c|c|c|c|c|}
\hline \multirow[t]{2}{*}{ mg sterol/100g oil } & \multicolumn{2}{|c|}{ CONTROL } & \multirow[b]{2}{*}{$\mathbf{L S}^{\mathbf{2}}$} & \multicolumn{2}{|c|}{3 HOURS } & \multicolumn{4}{|c|}{9 HOURS } \\
\hline & OLIVE $^{1}$ & AVOCADO ${ }^{1}$ & & OLIVE $^{1}$ & AVOCADO ${ }^{1}$ & $\mathbf{L S}^{\mathbf{2}}$ & OLIVE $^{1}$ & AVOCADO ${ }^{1}$ & $\mathbf{L S}^{2}$ \\
\hline Campesterol & $3.93 \pm 0.27$ & $18.36 \pm 1.44^{b}$ & $* *$ & $3.30 \pm 0.22$ & $14.47 \pm 1.23^{a}$ & $* *$ & $3.61 \pm 0.35$ & $14.85 \pm 0.99^{a}$ & $* * *$ \\
\hline Campestanol & $0.04 \pm 0.03$ & $0.43 \pm 0.03^{c}$ & $* * *$ & $0.02 \pm 0.01$ & $0.28 \pm 0.02^{b}$ & $* * *$ & $0.04 \pm 0.00$ & $0.04 \pm 0.02^{a}$ & ns \\
\hline Stigmasterol & $0.76 \pm 0.09^{a}$ & $1.11 \pm 0.12^{b}$ & $*$ & $1.23 \pm 0.13^{b}$ & $1.04 \pm 0.21^{b}$ & $\mathrm{~ns}$ & $0.89 \pm 0.04^{a}$ & $0.31 \pm 0.01^{a}$ & $* *$ \\
\hline Unknown 1 & $1.59 \pm 0.17$ & $3.62 \pm 0.08^{b}$ & $* * *$ & $1.09 \pm 0.08$ & $1.19 \pm 0.83^{a}$ & ns & $1.46 \pm 0.32$ & $1.82 \pm 0.17^{a}$ & ns \\
\hline Unknown 2 & $2.16 \pm 0.22^{a}$ & $30.39 \pm 0.34^{c}$ & $* * *$ & $1.66 \pm 0.88^{a}$ & $1.04 \pm 0.41^{b}$ & ns & $5.52 \pm 0.22^{b}$ & $0.00 \pm 0.00^{a}$ & $* * *$ \\
\hline Lanosterol & $0.45 \pm 0.06$ & $0.59 \pm 0.07^{b}$ & ns & $0.39 \pm 0.02$ & $0.40 \pm 0.07^{a}$ & ns & $0.43 \pm 0.03$ & $0.41 \pm 0.07^{a}$ & ns \\
\hline Sitosterol & $93.56 \pm 0.26^{b}$ & $251.07 \pm 20.71^{b}$ & $* *$ & $86.83 \pm 0.99^{a}$ & $192.19 \pm 18.78^{a}$ & $* *$ & $84.96 \pm 0.34^{a}$ & $216.63 \pm 13.44^{a b}$ & $* *$ \\
\hline Sitostanol & $0.61 \pm 0.02$ & $2.19 \pm 0.22^{b}$ & $* *$ & $0.53 \pm 0.06$ & $1.52 \pm 0.15^{a}$ & $* * *$ & $0.55 \pm 0.08$ & $1.38 \pm 0.08^{a}$ & $* * *$ \\
\hline$\Delta 5$ Avenasterol & $10.68 \pm 0.85$ & $9.42 \pm 1.69$ & ns & $9.19 \pm 0.74$ & $7.38 \pm 0.91$ & $\mathrm{~ns}$ & $10.11 \pm 0.93$ & $7.93 \pm 0.69$ & $*$ \\
\hline$\alpha$-amyrin & $1.56 \pm 0.14^{a}$ & $0.13 \pm 0.02^{b}$ & $* *$ & $1.42 \pm 0.12^{a}$ & $0.00 \pm 0.00^{a}$ & $* *$ & $1.31 \pm 0.10^{a}$ & $0.00 \pm 0.00^{a}$ & $* * *$ \\
\hline Lupeol+gramisterol & $0.40 \pm 0.05$ & $1.78 \pm 0.24^{b}$ & $* *$ & $0.32 \pm 0.01$ & $0.89 \pm 0.23^{a}$ & $*$ & $0.36 \pm 0.04$ & $1.38 \pm 0.17^{b}$ & $* *$ \\
\hline$\Delta 7$ sitosterol & $3.78 \pm 0.19^{b}$ & $2.82 \pm 0.39^{c}$ & $*$ & $3.28 \pm 0.15^{a}$ & $1.26 \pm 0.47^{b}$ & $* *$ & $3.75 \pm 0.25^{b}$ & $0.07 \pm 0.06^{a}$ & $* * *$ \\
\hline Cycloartenol & $43.69 \pm 3.29$ & $16.08 \pm 5.55$ & $* * *$ & $39.71 \pm 2.99$ & $14.18 \pm 2.24$ & $* * *$ & $41.02 \pm 0.58$ & $16.60 \pm 1.50$ & $* * *$ \\
\hline Cycloeucalenol & $1.37 \pm 0.16$ & $0.30 \pm 0.02^{b}$ & $* *$ & $1.27 \pm 0.05$ & $0.00 \pm 0.00^{a}$ & $* * *$ & $1.27 \pm 0.04$ & $0.00 \pm 0.00^{a}$ & $* * *$ \\
\hline$\Delta 7$ avenasterol & $0.48 \pm 0.03^{b}$ & $0.30 \pm 0.04^{c}$ & $* *$ & $0.36 \pm 0.03^{a}$ & $0.16 \pm 0.04^{b}$ & $* *$ & $0.43 \pm 0.06^{a b}$ & $0.08 \pm 0.00^{a}$ & $*$ \\
\hline Unknown 4 & nd & $0.08 \pm 0.00^{c}$ & & nd & $0.02 \pm 0.01^{b}$ & & nd & $\mathrm{nd}^{a}$ & \\
\hline Unknown 5 & nd & $6.55 \pm 0.10^{c}$ & & nd & $0.74 \pm 0.30^{b}$ & & nd & $\mathrm{nd}^{a}$ & \\
\hline 24-Methylenecycloartanol & $56.98 \pm 3.77$ & $1.13 \pm 0.01$ & $* * *$ & $51.98 \pm 4.13$ & $1.01 \pm 0.29$ & $* *$ & $50.75 \pm 0.43$ & $0.75 \pm 0.11$ & $* *$ \\
\hline Unknown 6 & nd & $0.30 \pm 0.07^{b}$ & & nd & $\mathrm{nd}^{a}$ & & nd & $\mathrm{nd}^{a}$ & \\
\hline Citrostadienol & $5.61 \pm 0.54^{b}$ & $9.03 \pm 1.83^{b}$ & $*$ & $4.53 \pm 0.06^{a}$ & $3.36 \pm 0.60^{a}$ & ns & $5.24 \pm 0.25^{a b}$ & $8.31 \pm 0.67^{b}$ & ** \\
\hline Total Phytosterols & $228.27 \pm 2.18^{b}$ & $339.64 \pm 4.88^{c}$ & $* * *$ & $206.83 \pm 2.44^{a}$ & $240.96 \pm 25.38^{a}$ & $*$ & $210.30 \pm 1.11^{a}$ & $270.44 \pm 17.70^{b}$ & $*$ \\
\hline
\end{tabular}


Figure 1. GC-MS chromatogram of the total ion count of TMS derivatives of phytosterols of olive and avocado oils. Peaks are identified as in Table 2.
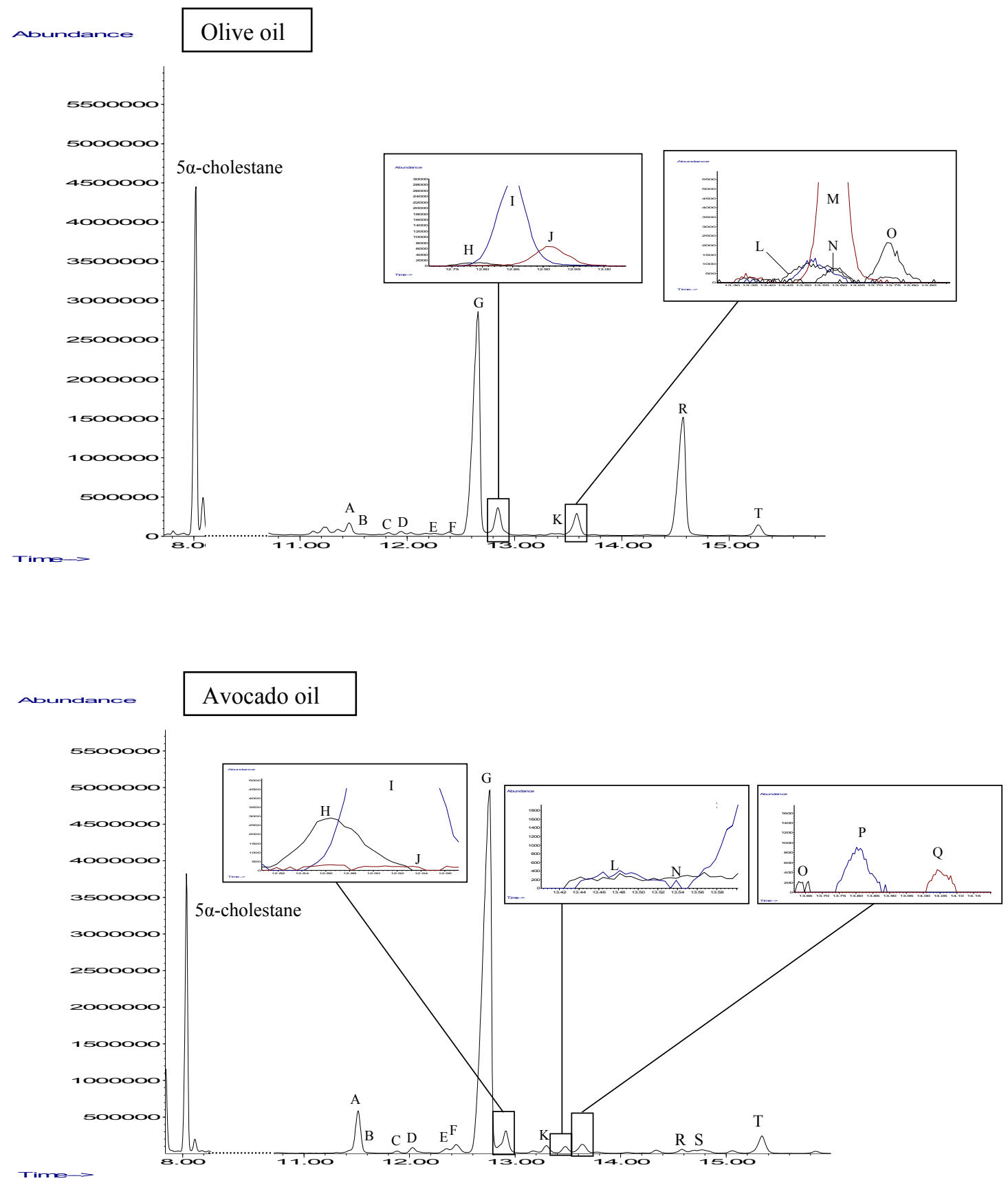
Figure 2. TBARs evolution during the heating process of the two types of oil (mg malondialdehyde/Kg oil).

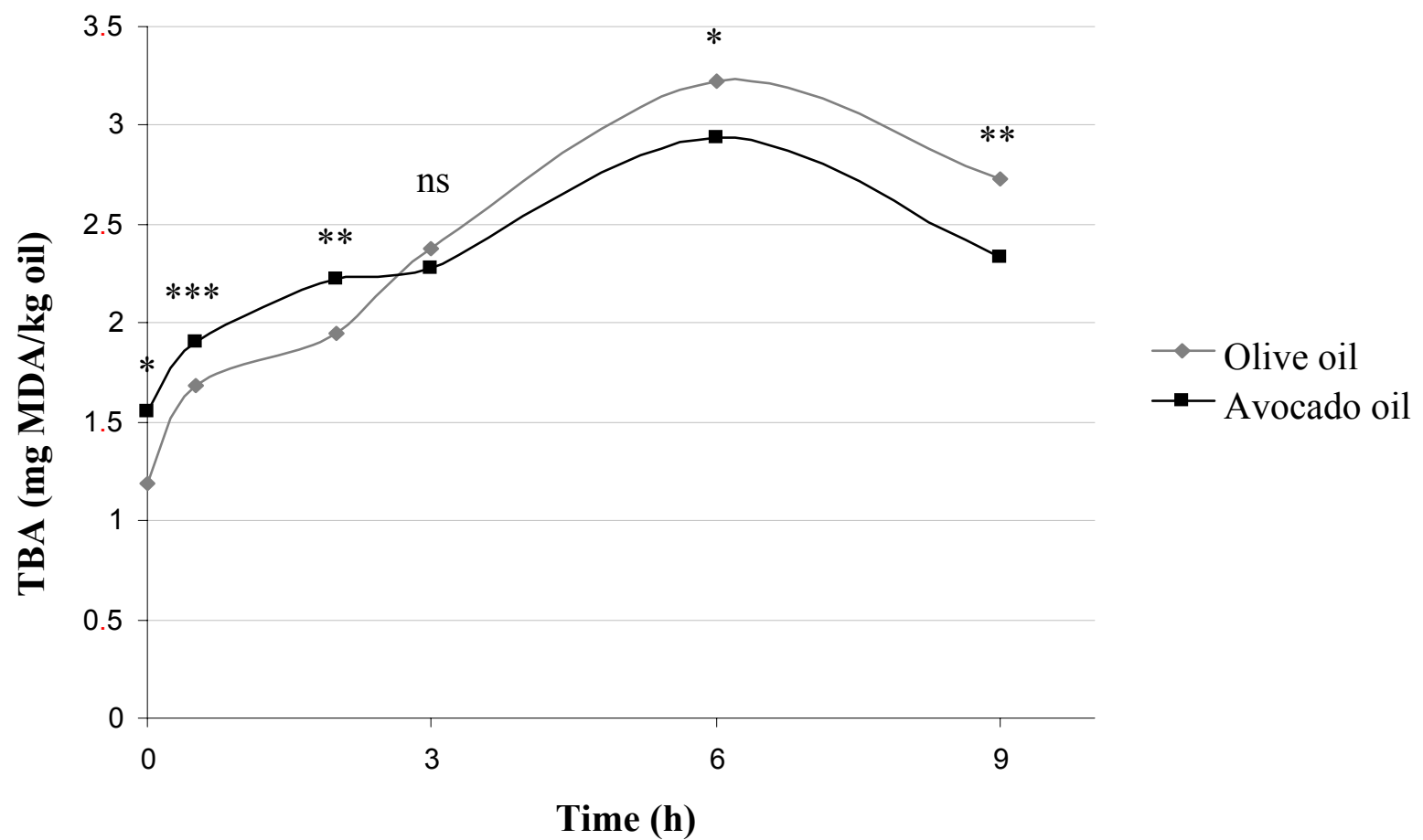

Level of significance for the Student t test that compares the two oils after different times of heating: $n s$ (not significant); $* p<0.05 ; * * p<0.01 ; * * * p<0.001$. 
Figure 3. Content of Vitamin $\mathrm{E}$ in olive and avocado oil during heat process (mg vit E/100 g oil).

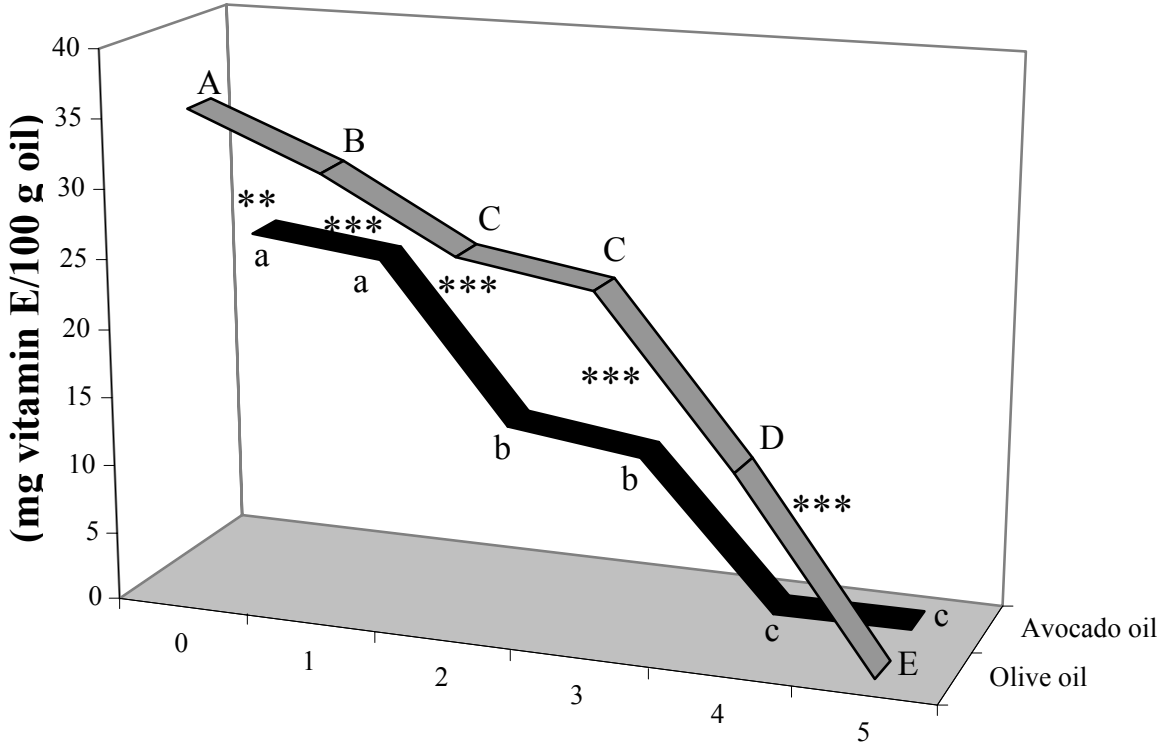

Time (h)

Different capital letters denote significant differences among olive oil after different times of heating and different lowercase letters denote significant differences among avocado oil after different times of heating $(p<0.05)$.

Level of significance for the Student $t$ test that compares the two oils after different times of heating: ${ }^{* *} p<0.01 ; * * * p<0.001$. 
